\section{SM Preventive \\ Medicine and \\ Public Health}

\section{Article Information}

Received date: Jan 21, 2019

Accepted date: Feb 11, 2019

Published date: Feb 14, 2019

\section{*Corresponding author}

Vanishree MK, Department of Public Health Dentistry, AECS Maaruti College of Dental Sciences and Research

Centre, Bengaluru, India,

Email: drvanishreemk@yahoo.com

Distributed under Creative Commons CC-BY 4.0

Keywords Gender; Inequality; Oral health care; Treatment need; Utilization

Article DOI 10.36876/smpmph.1027

\section{OPEN ACCESS}

\section{ISSN: 2576-4004}

\section{Gender Based Inequality and Use of Oral Health Care Services in Bangalore City}

\author{
Umashankar GK ${ }^{1}$, Vanishree $\mathrm{MK}^{2 \star}$ and Niharika Benjamin ${ }^{1}$ \\ ${ }^{1}$ Department of Public Health Dentistry, M.R. Ambedkar Dental College and Hospital, India \\ ${ }^{2}$ Department of Public Health Dentistry, AECS Maaruti College of Dental Sciences and Research Centre, \\ India
}

\section{Abstract}

Background: This study was carried out to assess the gender based inequality and use of oral health care services.

Material and Methods: A cross sectional study was undertaken among 15 teaching dental institute in Bangalore city. 1652 subjects were selected for the study and representative sample was drawn using a two stage random sampling technique. 200 females aged between 15 years and above were selected from each representative teaching dental hospital. Equal numbers of males belonging to same age group were selected for comparison. Interview was conducted and the information was collected on a Performa. Statistical analysis was done using SPSS version 19. Chi-square test and student test were used to detect difference.

Result: It was found that overall utilization of oral health care services was worse among females. More women perceived there oral health as poor, overall treatment needs in term of dental caries, periodontal health and prosthetic status was more for both genders. However, the required treatment needs were worst for females. There was a significant gender gap among females perception of gender inequality in use of oral health care both at home and at hospital. There was association between the perception of inequality and oral health care utilization and oral health outcome

Conclusion: The lower utilization of services, coupled with lack of importance and awareness regarding the oral health and the increasing burden of dental diseases especially among females can put this population under higher risk. Hence there is an urgent requirement for strategies to address the issues.

\section{Introduction}

Gender equality and women empowerment is recognized globally and is the key in achieving the overall development of the nation, state or region [1,2]. India stands at 53rd in gender gap ranking out of 58 countries of The Organization for Economic Co-operation and Development (OECD), and globally it ranked $129^{\text {th }}$ in gender inequality index $[3,4]$. Though Bangalore has the lowest sex ratio of 905/1000 males, the increase in domestic violence (8839 cases in 2009) and dowry cases (200 cases) every year indicates that status of women in Bangalore is still marginalized.

Gender inequality exists practically in every field and certainly in health. Literature review suggests that there is a gender difference in favor of men in the utilization of health services and more is spent per illness episode in men as compared to women, in all age groups. Recent third National Family Health survey (NFHS-3) survey showed $62 \%$ of women decide jointly with husband on own health care and only $48 \%$ of women aged 15-49 are allowed to go alone to health center. There is evidence that the attitude of health care providers is also influenced by these gendered norms in deciding the treatment [5-10].

Oro-dental diseases are emerging as serious public health problem in India [11]. Oral problems are not only causing pain, agony, functional and aesthetic problems but also causing loss of working man-hours [12]. Gender-specific differences in general health and disease may affect the oral health of women across her life span such as, hormonal influences on the periodontal health of women during puberty, pregnancy and menopause. Osteoporosis can worsen the preexisting periodontitis. Also women have differences in oral hygiene behavior and aesthetic needs and elderly women have more tooth loss compared to men. In the context of oral health care utilization the gender roles were not consistent as that of health. The Studies from United States showed that females visited dentists and used oral hygiene tools more frequently than males [13-17]. Study from sub Saharan Africa showed significantly more women visited subsidized clinics whereas men preferred private clinics, other studies did not find such a gender difference [18-20]. The majority of these data is from western countries moreover these studies have considered gender as a mere dichotomous variable without gendered roles. The extent to which it can be generalized to the patriarchal country like India is questionable. The present study is an attempt to know the gender based inequality and use of oral health care services. 


\section{Materials and Methods}

\section{Consent and Ethical Clearance}

Before conducting the study, informed consent was obtained from all the study subjects. This study was approved by Institutional Ethical Review Committee for Protection of Research Subjects (Ref. no. MRADC\&H/ECIRB/1090/2012-13) on $26^{\text {th }}$ November 2012. Permission for conducting study in selected colleges was obtained from concerned institutions.

\section{Study Design and Study Setting}

A cross sectional hospital based study was undertaken to assess the gender inequality in utilization of oral health care services in Bangalore.

Bangalore is one of the largest cities and is the fourth-largest metropolitan area in India. It is an epicenter of oral health care in Karnataka and consists of 15 teaching dental hospitals 1 government and 14 private which is the highest number of dental teaching hospitals in the country. These teaching dental institutes in Bangalore were the study setting for the present study.

\section{Sampling procedure and sample size}

A probability sampling method was used and two stages random sampling technique was adopted, at first the list of 15 teaching dental hospitals were the sampling frame, from this 1 government and three $\left(1 / 4^{\text {th }}\right)$ private hospitals was selected randomly (Lottery method ). In the second stage desired numbers of women belonging to 15 and above age groups (as we wanted to include at least one lower index age group as per WHO up to the maximum age) visiting the OPD of these hospitals were selected randomly as study participants.

Utilization rate of oral health care services for Bangalore in the teaching dental hospitals was calculated approximately using the out patients records of previous year which is $24.7 \%$. The total female population in Bangalore was 45,63,412 and approximately $60 \%$ belongs to the age group of 15-above (census India 2011).

Then the Sample size was estimated using utilization rate of $24.7 \%$ for the 2738047 (60\%) female population with $5 \%$ confidence interval and at $95 \%$ confidence level to be 800 and an equal number of male subjects belonging to the same age group was selected for comparison making a total sample size of 1600 population. This assured both the representativeness and randomness of the sample.

\section{Selection of Research Subjects}

A total of 1652 subjects were selected for the study. 200 females aged between 15 years and above willing to participate in the study were selected from the outpatient department of each representative sampled teaching dental hospital. An equal number of male subjects belonging to the same age group were selected for comparison. Participants who were Pregnant, suffering from severe chronic diseases and requiring any emergency care were excluded from the study.

\section{Data collection}

The research subjects were interviewed and information regarding socio-demographic variables, utilization of oral health care services and gender inequality were collected on a proforma.
The proforma consisted of 3 sections and Section I Consisted of Socio-Demographic information. Information like Age, place of residence, educational, occupation, income, religion, marital status and number of house hold members were considered. All the participants who were 15 years and above were considered for the study, they were grouped in to five age groups 15-24, 25-34, 35-44, 45-54, 55 and above. Place of residence was categorized into Urban, Peri-urban and rural areas.

Education level was classified based on the participants level of schooling and formal education and seven categories were formed (never attended school-1 primary schooling-2, higher primary-3, high school-4, pre university-4, graduation-5 and post graduation). Occupation was recorded according to International classification of labor organization 2010 for India, accordingly ten groups of occupation was recorded, senior officials and managers-1, professionals-2, technicians and associate professionals, clerk-4 shop market and sales work- 5 agriculture and fishery -6 craft related trade workers-7, machine operators and assemblers- 8 , and elementary occupation- 9 , because the present study was on gender the major occupation of females in our country is house wife and hence include the tenth group was added as occupation which cannot be classified under any of the above groups.

Religion and marital status was recorded as Hindu-1, Muslim-2, Christains- 3 and any other- 4 and marital status as married-1, widow/ spincter-2, never married-3, separated-4 and in relation -5. Monthly income of the family is recorded as per capita income and also the total number of members in the household was recorded, socio economic status was classified according to the BG Prasad's classification using consumer price index for the year 2012 and per capita income and they are grouped into social class I to Social Class V [21].

Section II consisted of the perceived experience of gender inequality and section III included measurement of oral health. These items were taken from the existing review of literature.

\section{Measurement of Gender inequality:}

In addition a 9 item questionnaire representing three dimensions of inequality societal, home and hospital were recorded on a 5 point likerts scale 0 being "never" and 4 being the "very often". The home dimension consisted of 5 items and the hospital dimension consisted of 4 items.

The scores were then summed and converted to the percentages by using the formula.

Total numbers of scores X 100 / Max score in the scale X total number of items.

The final values were categorized as those who did not perceive gender inequality, perceive Low, Moderate and High gender inequality.

Pilot study- Prior to the study, a pilot study was carried out on a sample of 50 adult patient attending OPD of private dental college to know the feasibility and to test the validity and reliability of the questionnaire. The Content validity ratio (CVR) was calculated. The items with lesser CVR were deleted. The internal consistency reliability was checked and Cronbach's alpha value was obtained as 0.71 . 
Table 1: Distribution of study participants according to socio-demographic factors.

\begin{tabular}{|c|c|c|}
\hline Demographic information & Frequency & Percentage \\
\hline \multicolumn{3}{|l|}{ Age in years } \\
\hline 15-24 Years & 464 & 28.1 \\
\hline 25-34 Years & 442 & 26.8 \\
\hline 35-44 Years & 323 & 19.6 \\
\hline 45-54 Years & 229 & 13.9 \\
\hline 55 Years and Above & 194 & 11.7 \\
\hline \multicolumn{3}{|l|}{ Education } \\
\hline Never Attended School & 81 & 4.9 \\
\hline Primary School & 48 & 2.9 \\
\hline Higher Primary & 118 & 7.1 \\
\hline High School & 468 & 28.3 \\
\hline Pre University & 292 & 17.7 \\
\hline Graduation & 562 & 34 \\
\hline Post graduation & 83 & 5 \\
\hline \multicolumn{3}{|l|}{ Occupation } \\
\hline Senior officers and Mangers & 17 & 1 \\
\hline Professionals & 54 & 3.3 \\
\hline $\begin{array}{l}\text { Technicians and associate } \\
\text { professional }\end{array}$ & 260 & 15.7 \\
\hline Clerks & 79 & 4.8 \\
\hline Shop and Market sale works & 242 & 14.6 \\
\hline Agriculture and fishery & 52 & 3.1 \\
\hline Craft and Craft Related Workers & 29 & 1.8 \\
\hline Machine operators and assemblers & 91 & 5.5 \\
\hline Elementary occupation & 82 & 5 \\
\hline Any other (House hold work, house wife) & 465 & 28.1 \\
\hline Students & 281 & 17 \\
\hline \multicolumn{3}{|l|}{ Social class } \\
\hline SES Class I & 192 & 11.6 \\
\hline SES Class II & 398 & 24.1 \\
\hline SES Class III & 431 & 26.1 \\
\hline SES Class IV & 545 & 33 \\
\hline SES Class $\vee$ & 86 & 5.2 \\
\hline \multicolumn{3}{|l|}{ Religion } \\
\hline Hindu & 1301 & 78.8 \\
\hline Muslims & 266 & 16.1 \\
\hline Christian & 78 & 4.7 \\
\hline Any other & 7 & 0.4 \\
\hline \multicolumn{3}{|l|}{ Marital Status } \\
\hline Married & 1077 & 65.2 \\
\hline Widowed/Spinster & 35 & 2.1 \\
\hline Never Married & 535 & 32.4 \\
\hline Separated & 3 & 0.2 \\
\hline In Relation & 2 & 0.1 \\
\hline \multicolumn{3}{|l|}{ Place of residence } \\
\hline Urban & 1508 & 91.3 \\
\hline Peri-urban/rural & 144 & 8.7 \\
\hline
\end{tabular}

\section{Training and calibration}

The investigators were trained on 10 randomly selected adults. Calibration of examiners was done on 20 adults who were examined twice using diagnostic criteria on successive days, and then the results were compared to know the diagnostic variability. Agreement for assessment was considered at $90 \%$. The research assistant was trained in entering data using the WHO Performa.

\section{Statistical analysis}

Statistical analysis was done using SPSS version 19.0 (Statistical Package for Social Sciences). The quantitative values were expressed as Mean and Standard Deviation and qualitative values in percentages. Chi-square test, student test was used to detect difference in distribution of dental service utilization in relation to the various independent variables and dependent variables within the population and between the populations. The statistical significance level will be fixed at 0.05 .

\section{Results}

The present study was conducted on a sample of 1652 outpatient who visited various teaching dental hospitals in Bangalore. Equal number of males (826) and females (826) were interviewed, belonging to $15-80$ years of age with the mean age of $35.47 \pm 14.50$ years for males and $34.58 \pm 13.56$ years for females (Table 1 ).

The gender differences in perception of inequality was observed, where most of the females perceived inequality compared to males (Table 2).

When the distributions of individual items were observed it showed that consistently the females had perceived gender inequality for all the items both in house and at hospital. However the percentage difference was high for the items in the house hold perception compared to the hospital (Table 3A, 3B).

The perception of gender inequality was associated with the time since last visit, compared to irregular visitors and these differences were statistically significant. Among males the similar difference were observed but was not statistically significant (Table 4).

When perception of gender inequality was compared with the delay in the visit it showed that $48 \%, 59.5 \%$ and $63.3 \%$ of the females had delayed the visit to dentist who perceived low moderate and high perception of inequality respectively. Among male subjects there

Table 2: Gender distribution of perceived gender inequality.

\begin{tabular}{|l|c|c|c|}
\hline \multirow{2}{*}{\multicolumn{1}{|c|}{ Percieved gender inequality }} & \multicolumn{2}{c|}{ Gender } & Total \\
\cline { 2 - 4 } & Male & Female & \\
\hline Did not perceive & 91 & 0 & 91 \\
& $(11.0)$ & 0 & $(5.5)$ \\
\hline \multirow{2}{*}{ Low Perception of gender inequality } & 587 & 75 & 662 \\
& $(71.1)$ & $(9.1)$ & $(40.1)$ \\
\hline Moderate Perception of gender inequality & 135 & 457 & 592 \\
& $(16.3)$ & $(55.3)$ & $(35.8)$ \\
\hline High perception of gender inequality & 13 & 294 & 307 \\
& $(1.6)$ & $(35.6)$ & $(18.6)$ \\
\hline
\end{tabular}

- Values in parenthesis are (\%).

- Subscript letter denotes a subset of gender categories whose column proportions significantly from each other at the .05 level. ( $Z$ test and $p$ value adjusted by Bonferroni Method). 
Table 3A: Distribution of study population according perceived gender inequality at home.

\begin{tabular}{|c|c|c|c|c|c|c|}
\hline \multicolumn{2}{|l|}{ Perceived gender inequality } & \multirow{2}{*}{$\begin{array}{c}\text { Never } \\
680(77.3)\end{array}$} & \multirow{2}{*}{\begin{tabular}{|l} 
Seldom \\
$25(27.2)$
\end{tabular}} & \multirow{2}{*}{$\begin{array}{c}\text { Some times } \\
21(10.1)\end{array}$} & \multirow{2}{*}{$\begin{array}{c}\text { Often } \\
59(19.5)\end{array}$} & \multirow{2}{*}{\begin{tabular}{|l|} 
Very often \\
$41(24.3)$ \\
\end{tabular}} \\
\hline My house hold resources (money) are not equally distributed between me & Males & & & & & \\
\hline and other members of the family for oral health care & Females & $200(22.7)$ & $67(72.8)$ & 187 (89.9) & $244(80.5)$ & $128(75.7)$ \\
\hline \multirow{2}{*}{ My family members ignored my oral health problem } & Males & $663(71.6)$ & 29 (29.6) & $49(27.5)$ & $49(22.2)$ & $49(22.2)$ \\
\hline & Females & $263(28.4)$ & $69(70.4)$ & $129(72.5)$ & $172(77.8)$ & $172(77.8)$ \\
\hline \multirow{2}{*}{$\begin{array}{l}\text { I feel I don't have freedom to go alone to the hospital for my own oral } \\
\text { health care }\end{array}$} & Males & $674(76.3)$ & $40(27.0)$ & $42(22.5)$ & $47(25.0)$ & $23(9.3)$ \\
\hline & Females & $209(23.7)$ & $108(73.0)$ & $145(77.5)$ & $141(75.0)$ & $223(90.7)$ \\
\hline \multirow{2}{*}{ I Can't decide on my own oral health care } & Males & $622(71.9)$ & $105(38.2)$ & $45(20.9)$ & $28(15.0)$ & $26(23.6)$ \\
\hline & Females & $243(28.1)$ & $170(61.8)$ & $170(79.1)$ & $159(85.0)$ & $84(76.4)$ \\
\hline \multirow{2}{*}{ I feel I don't have an equal access to health care /information } & Male & $309(76.5)$ & $462(67.8)$ & $18(7.4)$ & $2(1.0)$ & $35(29.7)$ \\
\hline & Females & $95(23.5)$ & $219(32.2)$ & $225(92.6)$ & $204(99.0)$ & $83(70.3)$ \\
\hline
\end{tabular}

Values in the parenthesis are percentages.

Table 3B: Distribution of study population according perceived gender inequality.

\begin{tabular}{|c|c|c|c|c|c|c|}
\hline \multicolumn{2}{|l|}{ Perceived gender inequality } & Never & Seldom & Some times & Often & Very often \\
\hline \multirow{4}{*}{ I feel My privacy is not respected in the hospital } & \multirow{2}{*}{ Males } & 739 & 7 & 35 & 22 & 23 \\
\hline & & -55.3 & -33.3 & -72.9 & -17.5 & -19.2 \\
\hline & \multirow{2}{*}{ Females } & 598 & 14 & 13 & 104 & 97 \\
\hline & & -44.7 & -66.7 & -27.1 & -82.5 & -80.8 \\
\hline \multirow{4}{*}{ I feel Confidentiality of my treatment is not protected. } & \multirow{2}{*}{ Males } & 696 & 30 & 43 & 24 & 33 \\
\hline & & -51.6 & -81.1 & -72.9 & -22.4 & -33.3 \\
\hline & \multirow{2}{*}{ Females } & 654 & 7 & 16 & 83 & 66 \\
\hline & & -48.4 & -18.9 & -27.1 & -77.6 & -66.7 \\
\hline \multirow{4}{*}{ I feel my decision on treatment was not considered by the dentist. } & \multirow{2}{*}{ Males } & 689 & 2 & 59 & 39 & 37 \\
\hline & & -51.6 & -22.2 & -33.9 & -55.7 & -57.8 \\
\hline & \multirow{2}{*}{ Females } & 646 & 7 & 115 & 31 & 27 \\
\hline & & -48.4 & -77.8 & -66.1 & -44.3 & -42.2 \\
\hline \multirow{4}{*}{$\begin{array}{l}\text { I feel the attitude of the staff /health personnel was negative in the } \\
\text { hospital }\end{array}$} & \multirow{2}{*}{ Males } & 678 & 4 & 69 & 37 & 38 \\
\hline & & -58 & -33.3 & -40.4 & -22.8 & -27.3 \\
\hline & \multirow{2}{*}{ Females } & 490 & 8 & 102 & 125 & 101 \\
\hline & & -42 & -66.7 & -59.6 & -77.2 & -72.7 \\
\hline
\end{tabular}

Values in the parenthesis are percentages.

were no differences in the distribution, subjects who delayed and did not delay the visit (Table 5).

The association between the reason for visit and the gender inequality showed that $44 \%, 53 \%$ and $52 \%$ female subjects visited the dentist with symptomatic reasons against $41.3 \%, 47 \%$ and $48 \%$ of asymptomatic visits with increase in the perception of the inequality from low to high perception of gender inequality respectively.
Among male subjects this was inversely associated and did not show significance in the analysis (Table 6).

It was observed that the prevalence of dental caries increased with the increase in the perception of the inequality for both the genders (Table 7).

When measured in terms of the periodontal diseases among males the CPI score normal was $19.8 \%$ and $17 \%$ in those who did not perceive and have low perception where as for females it was 
Table 4: Distribution of study population according to Gender, time since last visit and perception of gender inequality.

\begin{tabular}{|c|c|c|c|c|c|c|}
\hline \multirow[b]{2}{*}{ Perception of Gender Inequality } & \multicolumn{3}{|c|}{ Male } & \multicolumn{3}{|c|}{ Females } \\
\hline & $\begin{array}{l}\text { First Time } \\
\text { Visitors }\end{array}$ & $\begin{array}{c}\text { Visited } 12 \\
\text { months back }\end{array}$ & $\begin{array}{l}\text { Visited more than } 12 \\
\text { months }\end{array}$ & $\begin{array}{l}\text { First Time } \\
\text { Visitors }\end{array}$ & $\begin{array}{c}\text { Visited } 12 \\
\text { months back }\end{array}$ & $\begin{array}{c}\text { Visited more than } 12 \\
\text { months }\end{array}$ \\
\hline \multirow{2}{*}{ Did not perceive } & 43 & 28 & 20 & 0 & 0 & 0 \\
\hline & -47.3 & -30.8 & -22 & 0 & 0 & 0 \\
\hline \multirow{2}{*}{ Low Perception of gender inequality } & 266 & 137 & 184 & 27 & 13 & 35 \\
\hline & -45.3 & -23.3 & -31.3 & -36 & -17.3 & -46.7 \\
\hline \multirow{2}{*}{ Moderate Perception } & 65 & 30 & 40 & 179 & 122 & 156 \\
\hline & -48.1 & -22.2 & -29.6 & -39.2 & -26.7 & -34.1 \\
\hline \multirow{2}{*}{ High perception } & 7 & 2 & 4 & 142 & 52 & 100 \\
\hline & -53.8 & -15.4 & -30.8 & -48.3 & -17.7 & -34 \\
\hline \multirow{2}{*}{ Total } & 381 & 197 & 248 & 348 & 187 & 291 \\
\hline & -46.1 & -23.8 & -30 & -42.1 & -22.6 & -35.2 \\
\hline
\end{tabular}

Value in the parenthesis is percentage.

Table 5: Distribution of study subjects according Gender to delay in the Dental visits and perception of gender inequality.

\begin{tabular}{|c|c|c|c|c|}
\hline \multirow{3}{*}{ Perception of Gender Inequality } & \multicolumn{4}{|c|}{ Delay in dental visit } \\
\hline & \multicolumn{2}{|c|}{ Male } & \multicolumn{2}{|c|}{ Females } \\
\hline & Did not delay & Delayed & Did not delay & Delayed \\
\hline \multirow{2}{*}{ Did not perceive } & 48 & 43 & 0 & 0 \\
\hline & -52.7 & -47.3 & 0 & 0 \\
\hline \multirow{2}{*}{ Low Perception of gender inequality } & 295 & 292 & 39 & 36 \\
\hline & -50.3 & -49.7 & -52 & -48 \\
\hline \multirow{2}{*}{ Moderate Perception } & 67 & 68 & 185 & 272 \\
\hline & -49.6 & -50.4 & -40.5 & -59.5 \\
\hline High perception & 7 & 6 & 108 & 186 \\
\hline
\end{tabular}

- Categories are merged in to delay or not delayed

- Values in parenthesis is percentages

- Significance between the column percentages

$17.3 \%, 9.6 \%$ and $13 \%$ were with normal score who belonged to low, medium and high perception of gender inequality. According to CPI score bleeding on probing $17.3 \%, 21.2 \%$ and $21.8 \%$ of female subjects belonged to low, moderate and high perception of gender inequality respectively. $29.7 \%$ of male subjects belonged to did not perceive inequality. According to calculus Score it was observed that $33.3 \%$, $42.7 \%$ and $35.5 \%$ of the female subjects belonged to low moderate and high perception of gender inequality similarly for pocket depth $22.7 \% 21 \%$ and $23.1 \%$. Among males subjects $34.8 \%$, 36.3\% and $30.8 \%$ were with calculus score where as $24.7 \%, 28.1 \% 38.5 \%$ had pocket depth of more than $4 \mathrm{~mm}$ (Table 8).

\section{Discussion}

The present study is the first study to assess the perception of gender inequality related to oral health utilization,

The perception of gender inequality was assessed in two domains at home inequalities and at hospital / health setting inequalities, the findings of the present study indicates that more women perceived that there is a gender inequality in terms of the oral health both at home and at hospital, however the percentage of subjects with gender inequality at home was much higher compared to hospital settings which was favorable to men but not for women. United Nations world conference on women and Beijing platform for action proclaim equal rights for men and women at home and at work place. In a survey of 22 countries including India, it was reported that females from these countries are far more likely to perceive gender inequalities and 
Table 6: Distribution of study population according to Gender, the reason for visit and perception of gender inequality.

\begin{tabular}{|c|c|c|c|c|}
\hline \multirow{3}{*}{ Perception of Gender Inequality } & \multicolumn{4}{|c|}{ Reason for visit } \\
\hline & \multicolumn{2}{|c|}{ Symptomatic } & \multicolumn{2}{|c|}{ Asymptomatic } \\
\hline & Male & Female & Male & Female \\
\hline \multirow{2}{*}{ Did not perceive } & 62 & 0 & 29 & 0 \\
\hline & -68.1 & 0 & -31.9 & 0 \\
\hline \multirow{2}{*}{ Low Perception of gender inequality } & 368 & 44 & 219 & 31 \\
\hline & -62.7 & -58.7 & -37.3 & -41.3 \\
\hline \multirow{2}{*}{ Moderate Perception } & 80 & 242 & 55 & 215 \\
\hline & -59.3 & -53 & -40.7 & -47 \\
\hline \multirow{2}{*}{ High perception } & 5 & 153 & 8 & 141 \\
\hline & -38.5 & -52 & -61.5 & -48 \\
\hline \multirow{2}{*}{ Total } & 515 & 439 & 311 & 387 \\
\hline & -62.3 & -53.1 & -37.7 & -46.9 \\
\hline
\end{tabular}

- Categories are merged in to delay or not delayed

- Values in parenthesis is percentages

- Significance between the column percentages

Table 7: Distribution of the study population according to Gender, perception of gender inequality and prevalence of dental caries.

\begin{tabular}{|c|c|c|c|c|}
\hline \multirow[b]{2}{*}{ Perception of Gender Inequality } & \multicolumn{4}{|c|}{ Prevalence of dental caries } \\
\hline & \multicolumn{2}{|c|}{ Absence of dental caries } & \multicolumn{2}{|c|}{ Presence of dental } \\
\hline \multirow{2}{*}{ Did not perceive } & 20 & 0 & 71 & 0 \\
\hline & -22 & 0 & -78 & 0 \\
\hline \multirow{2}{*}{ Low Perception of gender inequality } & 95 & 8 & 492 & 67 \\
\hline & -16.2 & -10.7 & -83.8 & -89.3 \\
\hline \multirow{2}{*}{ Moderate Perception } & 27 & 39 & 108 & 418 \\
\hline & -20 & -8.5 & -80 & -91.5 \\
\hline \multirow{2}{*}{ High perception } & 5 & 49 & 8 & 245 \\
\hline & -38.5 & -16.7 & -61.5 & -83.3 \\
\hline \multirow{2}{*}{ Total } & 147 & 96 & 679 & 730 \\
\hline & -17.8 & -11.6 & -82.2 & -88.4 \\
\hline
\end{tabular}

- Categories are merged in to delay or not delayed

- Values in parenthesis is percentages

- Significance between the column percentages

men has better life than women. Though majority of the countries support gender equality it has not achieved effectively, including some developed countries [22,23].

Perception of inequality and oral health care utilization was assessed in terms of time since last visit, delay in visiting and reason for visit it clearly indicated that women, who perceived inequality had more irregular use, delay the visit, and visited more with symptomatic reason.

Further, inequality and oral health outcome was measured for two indicators of oral health that is dental caries and periodontal diseases in the present study. The prevalence of dental caries and gender inequality was present for both the sexes but females had greater inequality than males. This is in agreement with results of the study from Canada [24]. 
Table 8: Distribution of study population according to the Gender, Perception of gender inequality and periodontal status.

\begin{tabular}{|c|c|c|c|c|c|c|c|c|c|c|c|c|}
\hline \multirow{3}{*}{$\begin{array}{l}\text { Perception of Gender } \\
\text { Inequality }\end{array}$} & \multicolumn{12}{|c|}{ Periodontal status } \\
\hline & \multicolumn{2}{|c|}{ Normal } & \multicolumn{2}{|c|}{ Bleeding on probing } & \multicolumn{2}{|c|}{ Calculus } & \multicolumn{2}{|c|}{$\begin{array}{l}\text { Pocket measuring } \\
4-5 \mathrm{~mm}\end{array}$} & \multicolumn{2}{|c|}{$\begin{array}{c}\text { Pocket measuring more } \\
\text { than } 6 \mathrm{~mm}\end{array}$} & \multicolumn{2}{|c|}{$\begin{array}{l}\text { Did not record/ } \\
\text { Excluded }\end{array}$} \\
\hline & Male & Female & Male & Female & Male & Female & Male & Female & Male & Female & Male & Female \\
\hline & 18 & 0 & 27 & 0 & 33 & 0 & 11 & 0 & 1 & 0 & 1 & 0 \\
\hline Did not perceive & -19.8 & 0 & -29.7 & 0 & -36.3 & 0 & -12.1 & 0 & -1.1 & 0 & -1.1 & 0 \\
\hline \multirow{2}{*}{ Low Perception } & 101 & 13 & 96 & 13 & 204 & 25 & 145 & 17 & 22 & 2 & 19 & 5 \\
\hline & -17.2 & -17.3 & -16.4 & -17.3 & -34.8 & -33.3 & -24.7 & -22.7 & -3.7 & -2.7 & -3.2 & -6.7 \\
\hline \multirow{2}{*}{ Moderate Perception } & 22 & 44 & 21 & 97 & 49 & 195 & 38 & 96 & 3 & 13 & 2 & 12 \\
\hline & -16.3 & -9.6 & -15.6 & -21.2 & -36.3 & -42.7 & -28.1 & -21 & -2.2 & -2.8 & -1.5 & -2.6 \\
\hline \multirow{2}{*}{ High perception } & 0 & 41 & 3 & 64 & 4 & 104 & 5 & 68 & 1 & 10 & 0 & 7 \\
\hline & 0 & -13.9 & -23.1 & -21.8 & -30.8 & -35.4 & -38.5 & -23.1 & -7.7 & -3.4 & 0 & -2.4 \\
\hline \multirow{2}{*}{ Total } & 141 & 98 & 147 & 174 & 290 & 324 & 199 & 181 & 27 & 25 & 22 & 24 \\
\hline & -17.1 & -11.9 & -17.8 & -21.1 & -35.1 & -39.2 & -24.1 & -21.9 & -3.3 & -3 & -2.7 & -2.9 \\
\hline & \multicolumn{2}{|c|}{$P<0.05$} & \multicolumn{2}{|c|}{$P<0.05$} & \multicolumn{2}{|c|}{$P<0.05$} & \multicolumn{2}{|c|}{$P<0.05$} & \multicolumn{2}{|c|}{$P<0.05$} & & \\
\hline
\end{tabular}

Values in the parenthesis are percentages.

Chi square test Significance between male and female.

Not significant within the group.

Whether the need is subjective or objective, in terms of equality the two principles of equity are discussed equal access to equal need and equal utilization to equal need. the first one relates to opportunity to use the needed services rather than actual utilization, hence differences in rates of utilization by socio economic group do not reflect the actual inequalities the differences may be due to the lifestyle preferences/risk aversion.

Equal utilization for equal needs does not allow the differences of lifestyle preferences/level of risk aversion, hence the most appropriate principle of equality is equal access for equal need, and the results of the present study indicate a pattern close to the inverse care law that the females need for services both subjectively and objectively but face many barriers to use. Such differences are unacceptable and need a policy to make women's oral health as a priority.

This study is limited by the fact that when accessing the gender inequality in relation with oral health services we did not include the transgender as the third gender in our study which could have elaborated the discrimination and differences of gender in oral health use. The study included only the teaching dental hospitals for the study hence the data represents only the population who visit theses hospitals.

\section{Conclusion}

The lower utilization of services, coupled with lack of importance and awareness regarding the oral health and the increasing burden of dental diseases especially among females can put this population under higher risk. Hence there is an urgent requirement for strategies to address the issues. In the light of these problems the following strategies are recommended. a) Need to create an equal opportunity for both the genders to be part of the decision making process particularly in health and oral health.

b) Women empowerment and self reliance has to be strengthening through advocacy.

c) Integrated approach to address the issues related to inequality and gender discrimination by all the stakeholders like of policy makers, professionals and public

d) More gender sensitive hospital environment by sensitizing the hospital workers including the dentists and Para dental staff.

e) Measures to control the house hold discrimination especially for health and oral health should be given importance.

f) Establish a system in the teaching hospitals to identify patient/ victims of discrimination and to offer social support through counseling for family members and

g) Raise awareness of gender stereotypes to encourage equal sharing of the paid and unpaid work between men and women.

h) Promote family policies enabling both genders to balance between working and family responsibilities to ensure that both have an access to health care.

As the present study is a cross-sectional study it cannot tell the reasons associated with gender difference in Dental health care service utilization, hence further analytical studies are recommended.

\section{References}

1. United Nations General Assembly. United Nations Millennium Declaration, A res/55/2, 2000. 2000

2. Women and health: today's evidence, tomorrow's agenda. Geneva, WHO 2009. 
3. Women's Empowerment: Measuring the Global Gender Gap, Augusto Lopez Claros, Saadia Zahidi, and 2005 World Economic Forum. geneva.

4. Gender inequality index and indicators: human development report 2011 UNDP.

5. National sample survey organization (NSSO)1992 nss 42 round 1986-1987. government of India dept of statistics new delhi.

6. National council for applied economic research 1992 house hold survey of medical care. 2011

7. Madhiwalla N, Nandraj S, Sinha R. Health, households and women's lives: A study of illness and childbearing among women in Nasik district. Centre for Enquiry into Health and Allied Themes, Mumbai. 2000.

8. Nandraj S, Duggal R. Physical standards in the private health sector. Radica Journal of Health (New Series)1996; 2: 141-183.

9. National Family Health Survey (NFHS-3) India 2005-06 .Gender equality and women's empowerment in india. Ministry of Health and Family Welfare Government of India.

10. Ojanuga DN, Gilbert C. Women's access to health care in developing countries. Soc Sci Med. 1992; 35: 613-617.

11. Kadaluru UG, Kempraj VM, Muddaiah P. Utilization of oral health care services among adults attending community outreach programs. Indian J Dent Res. 2012; 23: 841-842.

12. Nanda Kishore KM. Public health implications of oral health-inequity in India J. Adv Dental Research. 2010; 1: 1-10.

13. Tomar SL, Azevedo AB, Lawson R. Adult dental visits in California: successes and challenges. Journal of Public Health Dentistry. 1998; 58: 275-280

14. Slack-Smith LM, Mills CR, Bulsara MK, O'Grady MJ. Demographic, health and lifestyle factors associated with dental service attendance by young adults. Aust Dent J. 2007; 52: 205-209.
15. Richard J Manski. Dental services -An analysis of utilization over 20 years JADA. 2001; 132: 655-664.

16. Davidson PL. Determinants of Dental Care Utilization for Diverse Ethnic and Age Groups. Adv Dent Res.1997; 11: 254-262.

17. Jackson Brown L. Dental care utilization: how saturated is the patient market? JADA. 1999; 130: 573-580.

18. Varenne B, Msellati P, Zoungrana C, Fournet F, Salem G. Reasons for attending dental-care services in Ouagadougou, Burkina Faso. Bull World Health Organ. 2005; 83: 651-655

19. Watt R, Sheiham A. Inequalities in oral health: a review of the evidence and recommendations for action. Br Dent J. 1999; 187: 6-12.

20. Maharani DA, Perceived need for and utilization of dental care in Indonesia in 2006 and 2007: a secondary analysis. J Oral Sci. 2009; 51: 545-550.

21. Prasad BG. Social classification of Indian families. J Indian Med Assoc 1961; 37: $250-251$

22. Olanrewaju I .An Audit of Pattern of Patients' Presentation at the Periodontics Clinic of the University College Hospital, Ibadan. Annals of Ibadan Postgraduate Medicine. 2009; 7: 16-20.

23. Gender Equality Universally Embraced, But Inequalities Acknowledged Men's Lives Often Seen as Better. Nation Pew Global Attitudes Survey A special report done in association with The International Herald Tribune. 2010

24. Ravaghi V, Quinonez RV, Allison PJ: The magnitude of oral health inequalities in Canada: Findings of the Canadian health measures survey. Community Dent Oral Epidemiol. 2013; 41: 490-498. 